\title{
DISTILLED WATER IN PYORRHEA
}

\author{
By DOW R. BEEBE, D.D.S., Bridgeport, Connecticut
}

$\mathrm{A}^{\mathrm{T}}$ T THE present time every dental magazine has articles on the treatment of pyorrhea alveolaris, most of which have real merit, but it is not the object of this article to specify any particular treatment but rather to tell of an aid to any treatment.

The writer has prescribed to his patients for the past twenty years the liberal and continual use of distilled water, and finds where it is faithfully used that the deposits on the teeth are soft, if there are any at all, and there is no irritation caused by whatever deposit there is.

You who have automobiles know that the directions as regards the care of the storage battery tell you to use distilled water. Why? Because the makers of the battery know that any minerals in other than distilled water will affect the solution and plates in the battery. So the same applies to the adult human system. The writer fully believes and it is carried out in practice that at the age salivary calculus begins to deposit, the system is showing that it has an excess of minerals by depositing calculus on the surfaces of the teeth. It is then time, after proper prophylactic precautions have been taken, to prescribe the drinking of distilled water to the exclusion of other water. The tea, coffee and cocoa should be made with distilled water. You should specify "double distilled water," as the kind used for storage batteries is not pure enough.

It is the writer's opinion that where considerable deposits of salivary calculus are on the teeth that you will finf symptoms of calcic deposits thruout the system, and the curing of pyorrhea does not necessarily mean that the patient will be restored to health unless the cause, viz., calcic deposits, is removed, permanently. It is also necessary that the patient should have an active system and the bowels kept open, preferably without the use of either laxatives or cathartics but with proper foods.

Physicians have been advising their patients for years to "drink lots of water." That was good as far as it went, but had they specified "double distilled water" they would have been on the right track. So let me repeat one suggestion, have the patient drink and use the distilled water exclusively and you watch the results.

Some one may ask, "why will distilled water prevent the depositing of salivary calculus"? The answer is, as there are no minerals in the distilled water, the excess of minerals in the system will be taken up by it. Others may say, "the system needs minerals." Surely, but proper foods will furnish all that is needed. Again, "will not faucet or spring water take up the excess minerals?" No, because any drinking water has already taken up all the minerals it can and more minerals would make it cloudy or muddy.

Do not confound boiled water with distilled water. Boiled water still has the minerals in it, only the animal matter has been eliminated.

The water company in our city manufactures the distilled water for drinking purposes and when the water is served cold is as good a drink as any spring water. If distilled water cannot be purchased, advise the patient to buy a still and distill his own. 